\title{
Difference between the biologic and chronologic age as an individualized indicator for the skincare intensity selection: skin cell profile and age difference studies
}

\author{
Yurij Sukhovei ${ }^{1}$, Elena Kostolomova', Irina Unger ${ }^{1}$, Andrey Koptyug ${ }^{2^{*}}$ (D) and Denis Kaigorodov ${ }^{1}$
}

\begin{abstract}
Background: The present research addresses the issue of skin aging and corresponding skin treatment individualization. Particular research question was on the development of a simplified criterion supporting patientspecific decisions about the necessity and intensity of skin treatment. Basing on published results and a wide pool of our own experimental data, a hypothesis is formulated that a difference between biologic and chronologic age can be used as a powerful indicator of skin aging.

Methods: In the present paper, we report the results of studies with 80 volunteers between 15 and 65 years of age linking skin cell profile parameters to biologic and chronologic age. Biologic age was calculated using the empirical expressions based on the forced vital lung capacity, systolic blood pressure, urea concentration, and blood cholesterol level. Epidermis and derma cellular structures were studied using skin biopsy samples taken from the gluteal region.

Results: The present study supports the conclusion that biologic and chronologic age difference is changing in the progress of life. Our studies are showing that time point when calculated biologic age becomes equal to the chronologic one reflecting the onset of specific changes in the age dependencies of experimentally measured skin cell profile parameters. Thus, it is feasible that a difference between chronologic and individually assessed biologic age indeed reflects the process of skin aging.

Conclusions: With all reservations to the relatively small number of study participants, it seems feasible that a difference between biologic and chronologic age can be used as an indicator of skin aging. Additional research linking blood immune profile and skin topography to the difference of biologic and chronologic age (reported in the following paper) provides further support for the formulated hypotheses. So, a difference between calculated biologic age and chronologic age can be used as an individualized criterion supporting decisions on skin treatment strategies. Further research involving larger numbers of participants aimed at optimizing the expressions for calculating biologic age could lead to reliable and easily available express criterion supporting the decision for the individualized skin treatment.
\end{abstract}

Keywords: Skin aging, Biologic and chronologic age difference, Skin cell profile, Individualized skin treatment

\footnotetext{
* Correspondence: andrey.koptyug@miun.se

${ }^{2}$ SportsTech Research Centre, Mid Sweden University, Akademigatan 1,

Östersund, Sweden

Full list of author information is available at the end of the article
}

(c) The Author(s). 2019 Open Access This article is distributed under the terms of the Creative Commons Attribution 4.0 International License (http://creativecommons.org/licenses/by/4.0/), which permits unrestricted use, distribution, and reproduction in any medium, provided you give appropriate credit to the original author(s) and the source, provide a link to the Creative Commons license, and indicate if changes were made. The Creative Commons Public Domain Dedication waiver (http://creativecommons.org/publicdomain/zero/1.0/) applies to the data made available in this article, unless otherwise stated. 


\section{Introduction}

The appearance of human skin commonly affects external perception and can have significant life consequences (Graham and Kligman 1985; Berry and McArthur 1986; Kligman and Graham 1986; Waters 1986; Steele et al. 1993; Koblenzer 1996; Gupta 1998; Gilchrest 2003; Gupta and Gupta 2003; Koblenzer 2003; Gupta and Gilchrest 2005; Lai et al. 2011; Rawal and Anshu 2019). Today active skincare starts from a rather early age and is quite common for both genders (Brdar et al. 1996; Sturrock and Pioch 1998; York-Goldman and Goldman 2001; Kokoi 2011; Safe Cosmetics for Young Children 2012; Teen Survival Guide 2013; Gupta and Arora 2013; Cash and Cash 1982). Modern lifestyle demands quick responses to all stimuli and the pressure of social environment and media glorifying personal beauty is quite intense. Thus, with increasing variety and availability of skincare products, it is not unusual to choose intensive skincare methods promising fast visible effects. In many cases, intense interventions are started earlier than it is necessary, and products designed for intensive skin treatment are often used without adequate substantiation. Such treatment may result in only negligible undesired consequences, but it can inflict certain damage (which potentially could be long lasting). The use of cosmetic and skincare products at an early age is becoming quite widespread (Safe Cosmetics for Young Children 2012) already forcing legislative interventions regulating the market. In 2012, a new Resolution was adopted by the Council of Europe's Committee of Ministers on safety criteria for cosmetic products intended for infants (Safe Cosmetics for Young Children 2012). Understanding possible health effects of the skincare products used improperly or too intensely is growing (Cash and Cash 1982; de Groot 2001; Little et al. 2007; Cheng et al. 2010; Khan and Khan 2013; Bhomick and Rao 2014; Konduracka et al. 2014; Girdwichai et al. 2018), but so far, there are no express methods for individualizing skincare or treatment. Plainly speaking, it is desirable to have some easy individualized indicators showing if in the particular case the skin is "young enough" and does not need intense treatment, or it is already "aging" and certain degree of treatment (moderate or intense) may be required for supporting effective decision-making for cosmetics and medicine.

One of the obvious observations coming from everyday life is that some people are "looking younger than their age" (Christensen et al. 2004; Gunn et al. 2009) pointing to the difference between the chronologic age and the perceived one. It may seem that perceived quality of our skin may be safely used as a criterion to determine if the skin needs serious treatment. However, very often the situation is biased by various factors including sociological and psychological ones. An individual decision on skincare is also significantly biased by self- perception. Another possible criterion is the chronologic age. However, it was shown that using chronologic age even together with the perceived one as the only indicator for starting intensive skin treatment could be misleading (Anderson and Parrish 1981; Anderson and Parrish 1982; Zhang and Duan 2018). It is mainly due to the large individual variations between different people even within the same chronologic age group. To account for at least some individual differences parameters like social age, psychological age and biologic age were introduced (Furukawa et al. 1975; Sanders and Newman 2013; Kim and Jazwinski 2015; Bulpitt et al. 1994; Kwon and da Vitoria Lobo 1999; Guinot et al. 2002; Gunn et al. 2008; Matts 2008; Nielsen et al. 2008; Dykiert et al. 2012; Porcheron et al. 2013; Coma et al. 2014; Krištić et al. 2014; Shetage et al. 2014; Trojahn et al. 2015a, 2015b, 2015c; Jia et al. 2017; Kang et al. 2017; Wang and Dreesen 2018). Among these, the biologic age concept and the frailty index in a cumulative way reflecting overall health status are supposed to be the most adequate indices representing age-related changes in the human body and skin. Though mentioned above indices are based on the objective data commonly available or easily obtainable for each person, neither of them was proven totally reliable for determining if the skin of a particular person needs special care and, if so, how intense such care should be. There are also suggestions that using skin analysis methods more sensitive to the intrinsic rather than extrinsic skin features (Guinot et al. 2002; Sanders and Newman 2013; Krištić et al. 2014; Trojahn et al. 2015a, 2015b, 2015c; Wang and Dreesen 2018) may be preferable for the express assessment of the perceived age (Gunn et al. 2008; Coma et al. 2014) together with the methods assessing skin roughness (Edwards et al. 2003; Jacobi et al. 2004; Masuda et al. 2014; Trojahn et al. 2015a, 2015b, 2015), or skin mechanical properties (Rodrigues 2001; Luebberding et al. 2014; Woo et al. 2014; Coltman et al. 2017). Nevertheless, experimental methods bringing detailed quantifiable information are often demanding complex skin or blood analysis and corresponding equipment with lengthy and expensive measurement procedures. Modern research also links the state of the human skin to the immune system status and other molecular-level parameters (Hall 1985; Kupper and Fuhlbrigge 2004; Alonso-Fernández and de la Fuente 2011; Mann et al. 2012; Castelo-Branco and Soveral 2014; Martínez de Toda et al. 2016; Csaba 2019). So far, there is no consensus which (if any) of the methods or accessible parameters or their simple combinations can be used in everyday practice as express indicators for determining if skincare treatment should be used at all, and if so how intensive it should be.

There are different approaches used in determining biologic age, and different expressions for biologic age 
calculations exist (Furukawa et al. 1975; Brown and Forbes 1976; Webster and Logie 1976; Borkan and Norris 1980; Ludwig and Smoke 1980; Voitenko and Tokar 1983; Hall 1985; Dean 1986; Dean 1998; Bulpitt et al. 1994; Uttley and Crawford 1994; Jackson et al. 2003; Kupper and Fuhlbrigge 2004; Beloserova 2006; Introna and Campobasso 2006; Klemera and Doubal 2006; Kaczmarek and Lasik 2006; Cho et al. 2010; Alonso-Fernández and de la Fuente 2011; Naylor et al. 2011; Smith and Brownless 2011; Mann et al. 2012; Wiweko et al. 2013; Castelo-Branco and Soveral 2014; Mitnitski and Rockwood 2014; Belsky et al. 2015; Cossio-Bolaños et al. 2015; Kim and Jazwinski 2015; Jee 2016; Jia et al. 2016; Martínez de Toda et al. 2016; Nedelec et al. 2016; Belsky et al. 2017; Jia et al. 2017; Kang et al. 2017; Csaba 2019). Such expressions are developed mainly for revealing the factors influencing longevity and mortality, and for studying the onset of aging. It is also suggested, that biologic age for different organs can be different even for the same subject. Recent research following the development of more than 900 individuals with the same chronologic age have revealed that good criteria can be constructed based on the comparison of the biologic and chronologic age dynamics (Belsky et al. 2015; Belsky et al. 2017) well reflecting the deterioration of general health and its self-perception, objective physiologic parameters, cognitive functions, motorics and balance. One of the general conclusions drawn from the analyzed data was that a pace of aging (calculated using yearly changes of biologic age-related parameters) was increasing when biologic age was becoming higher than chronologic one. Basing on the suggestions that mentioned difference of biologic age estimations and chronologic age reflects the increasing pace of aging, we have hypothesized that the age at which chronologic and estimated biologic age coincide may be used for constructing an express criterion of aging. In particular, it is hypothesized that a simplified criterion basing on the concept of biologic age can support individualized decisions and for cosmetics and medical practitioners. A corresponding approach can be using a limited number of parameters easily available from non-specialized hospitals, clinics or other certified health services thus providing a rapid cost-effective support for decision making on the individualization of skin treatment. Thus, main purpose of present study was to assess if the difference between biologic age (calculated basing on one of the simplified accepted procedures similar to the ones described by Webster and Logie 1976) and chronologic age (taken from identity documents) can be correlated to the objective measurable parameters of the epidermis and derma, and the immune system status. Moreover, if such correlations exist and are strong, with further detailed studies this may provide a valid basis for designing an individual indicator for selecting proper skincare.

Over the years, research has shown that human aging is associated with the changes in numerous factors and measurable parameters (e.g. Brown and Forbes 1976; Hall 1985; Nakamura et al. 1988; Montagna and Carlisle 1990; Bulpitt et al. 1994; Kupper and Fuhlbrigge 2004; Introna and Campobasso 2006; Gilchrest and Krutmann 2006; Johnson 2006; Gruenewald et al. 2006; Klemera and Doubal 2006; Maggio et al. 2006; Simm et al. 2008; Sprott 2010; Stowe et al. 2010; Alonso-Fernández and de la Fuente 2011; Krueger et al. 2011; Mather et al. 2011; Smith and Brownless 2011; Farage et al. 2013; Farkas et al. 2013; Holly et al. 2013; Castelo-Branco and Soveral 2014; Freis et al. 2014; Belsky et al. 2015; Cohen et al. 2015; Trojahn et al. 2015a, 2015b, 2015c; Watanabe et al. 2015; Jee 2016; Jia et al. 2016; Martínez de Toda et al. 2016; Passarino et al. 2016; Belsky et al. 2017; Chalyk et al. 2017; Csaba 2019). In addition, today, it is assumed that multibiomarker algorithms provide more reliable results (e.g. Gruenewald et al. 2006; Stowe et al. 2010; Mather et al. 2011; Belsky et al. 2015; Cohen et al. 2015; Watanabe et al. 2015; Passarino et al. 2016; Belsky et al. 2017). Unfortunately, multibiomarker and other multiparametric algorithms often demand relatively complicated procedures for data collection and are hard to use for express assessment. With wider availability of modern methods number of measurable parameters that could be included into consideration is continuing to grow (e.g. Watanabe et al. 2015, describing the application of NMR relaxometry measuring the coupling of water protons to the tissue for assessing facial aging).

Basing on available experimental results and literature data analysis following specific hypothesis was formulated:

a difference between the chronologic and biologic age can be used as an express individualized indicator of skin aging helping in decision taking on the skin treatment.

We have deliberately selected a limited set of tests for assessing the skin status (topography, moisture, elasticity, sebum level, cell structure), and the status of the immune system (basing on the blood tests) as a basis for potential skin aging criterion (indicator). In the process of selection, the methods common for microbiology and easily available for the modern laboratory were chosen to evaluate the limitations of using a smaller number of parameters for constructing an assessment criterion.

The present paper describes the experimental studies of the parameters reflecting skin cellular structure and their correlations with the biologic and chronologic age difference testing the formulated hypothesis. The following paper will present the results of experimental studies of the parameters reflecting skin state (moisture, sebum, roughness) and overall immune status as well as measured parameter correlations with the biologic and 
chronologic age difference and cross-correlations in support of the stated hypothesis.

\section{Methods}

Eighty healthy volunteers (40 male and 40 female) 15 to 65 years (chronologic age, $C A$ ) predominantly living in urban areas took part in the studies. The chronologic age of the participants was recorded from the identity documents. No pre-selection according to the health conditions or perception of the skin quality was involved. All procedures were conducted by the qualified personnel in accordance with principles of the Declaration of Helsinki and its amendments (World Medical Association Declaration of Helsinki. Ethical Principles for Medical Research Involving Human Subjects, 2013). All participants were properly informed on the nature of studies and specific procedures and gave signed written consent. The consent forms and the plans for the research were approved by the Ethics Commission of the Institute of Clinical Immunology (IRB 1025402458740) according to the formal requirements issued by the State Department of Health of the Russian Federation. In the presently discussed part of the overall study, the following aspects and parameters of the participants were assessed: calculated biologic and chronologic age of the participant and functional (cellular) state of the epidermis and derma.

The average age of the male and female participants was $39.05 \pm 2.28$ and $39.48 \pm 2.28$ years correspondingly. Body mass index (BMI) and interval boundaries were calculated according to the accepted formula (Nuttall 2015; Sochung 2015; Misra 2019):

$$
B M I=\text { weight }[k g] / h e i g h t^{2}\left[m^{2}\right]
$$

Note that with the approach to the biologic age $(B A)$ calculations used in this research, young age is corresponding to $B A>C A$, which may be to some extent counterintuitive. It is opposite to what was reported in some other papers when using different expressions for $B A$ calculations, giving $B A<C A$ for younger age (e.g. Voitenko and Tokar 1983; Jia et al. 2017; Kang et al. 2017).

\section{Calculation of the biologic age}

Biologic age was calculated basing on the forced vital lung capacity $(\boldsymbol{F V} \boldsymbol{C}$, liter), systolic blood pressure $(S B P$, $\mathrm{mm} \mathrm{Hg})$, urea concentration in urine $(U C, \mathrm{mg} / 100 \mathrm{ml})$ and blood cholesterol level (measured as the concentration of $\mathrm{Ca}$ in the blood serum, $B C a, \mathrm{mg} / 100 \mathrm{ml}$ ) using the empirical expressions suggested in (Beloserova 2006), derived following the approach developed in the papers (Borkan and Norris 1980; Voitenko and Tokar 1983; Dean 1986; Dean 1998). Following empiric expressions (different for male and female) common for the gerontology research in Russia were used for the calculations of biologic age (BA) (see Beloserova 2006):

$$
\text { for female } \quad \begin{aligned}
B A= & 51.01 \\
& +0.84 * U C-5.53 * F V C \\
& +0.2 * S B P \\
& +0.093 * B C a-5.53 * U C \\
\text { for male } \quad B A= & 93.86 \\
& +0.44 * U C-4.92 * F V C \\
& +0.19 * S B P \\
& +0.10 * B C a-9.01 * U C
\end{aligned}
$$

Vital lung capacity, the volume of air that can forcibly be blown out after full inspiration, was measured using a medical spirometer common for general hospitals. Systolic blood pressure was measured according to standard medical procedure using cuff tonometry. Blood and urine tests were done using cuff tonometer by a certified biomedical laboratory of a general hospital according to standard medical procedures. Blood cholesterol level was measured in venous blood serum using biochemical analyzer StatFax 1904+ by Awareness Technology, USA, with a test system from the same manufacturer according to the recommended test protocol. Cholesterol level for all participants was within the normal levels (3.36 to $\left.8.03 \times 10^{-3} \mathrm{~mol} / \mathrm{l}\right)$, but not all of them have had the levels within recommended limits (below $5 \times 10^{-3} \mathrm{~mol} / \mathrm{l}$ ).

\section{Assessment of the skin cellular structure}

Epidermis and derma cellular structure was studied, including the relative numbers of endothelial cells, endotheliocytes, keratinocytes, mastocytes and fibroblasts. These studies were carried out using the skin biopsy samples. Skin samples were acquired from the gluteal region using punch skin biopsy (disposable punchers DERMOPUNCH, diameter $2 \mathrm{~mm}$, by Sterylab, Italy). Cell suspension was prepared using the disaggregation system Medimachine (by Becton Dickinson Biosciences, USA). Skin sample together with $1 \mathrm{ml}$ of isotonic solution $(0.9 \%$ $\mathrm{NaCl}$ ) was disaggregated for 30 seconds. After that cell suspension was filtered (Filicons by Becton Dickinson Biosciences, USA, pore diameter $50 \mu$ ), residue was centrifuged for 5 minutes at $1500 \mathrm{rpm}$ and lighter fraction was removed. Cell concentration in the resulting sample was $1 \times 10^{6} \mathrm{ml}^{-1}$. Following analysis was carried out using Cytomics FC500 Flow Cytometry Analyzer (Beckman Coulter Inc., USA) using specific markers CD49f, CD44, CD45, CD14, CD207, CD146, CD249, CD3, CD4, CD8, CD19, CD16, CD56 fluorochrome-conjugated to fluorescein isothiocyanate (FITC), phycoerythrin (PE), PE-Texas red (ESD), PE/CY5 (PC5) and PE/CY7 (PC7), all by Beckman Coulter Inc., USA. Prior to the analysis cells were re-suspended in $50 \mu \mathrm{l}$ of phosphate-buffered saline 
(PBS) and stored at $+4{ }^{\circ} \mathrm{C}$ for 20 minutes. During each test, 50000 to 75000 cells were analyzed. Cell vitality was studied using 7-amino-actinomycin D RUO (7AAD, by Beckman Coulter Inc., USA) staining. Skin-resident macrophage concentration and activity was studied using the same biopsy samples as used for the skin cell studies under flow cytometry.

These parameters in the further research were crosscorrelated with the skin topography parameters and the parameters extracted from the blood immunology tests. Corresponding results will be presented in the following paper.

\section{Statistical analysis}

Pearson statistical and correlation analysis was carried out using the software package IBM SPSS Statistics Base v 22.0. Though the data sample size is not large enough to suggest adequate statistical analysis, certain preliminary conclusions could be already drawn.

\section{Results}

A large pool of experimental data was acquired and analyzed in the present study. Here we report on the data analysis and the most representative results for the parameters reflecting skin cellular structure and their correlations with the biologic and chronologic age.

\section{BMI Index distribution of the participants}

Figure 1 presents the BMI indices in the participant subgroups according to the chronologic age (a), and a number of the participants corresponding to BMI sub-groups (underweight, normal, overweight and obese) (b). Table 1 presents the average weight of participants in chosen BMI sub-groups. Corresponding boundaries of the BMI are taken to be < 18.50 for underweight; between 18.50 and 24.99 for normal; between 25.00 and 29.99 for overweight and $\geq 30 \mathrm{~kg} / \mathrm{m}^{2}$ for obese (Nuttall 2015; Sochung 2015; Misra 2019). The overall picture is reflecting a common trend for the urban population, showing certain tendency to be overweight and even obese, especially for the younger people, and between 55 and 60 years. With the elder people, there is a tendency for increasing weight with growing age, most probably related to decreasing physical activity.

\section{Biologic and chronologic age, their difference and subject sub-group selection}

For each of the participants, their biologic age was calculated according to the expressions (2) and (3). Figs. 2 and 3 present the plots of calculated biologic $(B A)$ age against chronologic one $(\boldsymbol{C A})$ for all participants (Fig. 2) and for male and female participants separately (Fig. 3).

Following trend lines are added for comparison: solid line for the dependence $B A=C A$, dotted line for the linear approximation of experimental data, and double dotted line for the trend of the perceived age. Trend line expression for the dependence of perceived age $(P A)$ on the chronologic one is constructed using the data from the papers (Gunn et al. 2008; Coma et al. 2014):

$$
P A=17.64+0.71 C A
$$

Comparing Figs. 2 and 3, it could be noted that corresponding trends are much clearer, if we use different expressions for calculating biologic age for male and female participants. For the younger people biologic age, calculated using the approach described above is on average larger than the chronologic one. It is counterintuitive (one would think of "seemingly younger than the age" in this case), and often differs from the ways other researchers calculate $B A$ (e.g. Voitenko and Tokar 1983; Belsky et al. 2015; Belsky et al. 2017; Kang et al. 2017), but this is the way with expressions for $B A$ accepted in Russian gerontology research (Beloserova 2006). After $35-45$ years, calculated biologic age becomes smaller than chronologic age (Figs. 2 and 3). It is noticeable that the crossover point (when $B A$ becomes

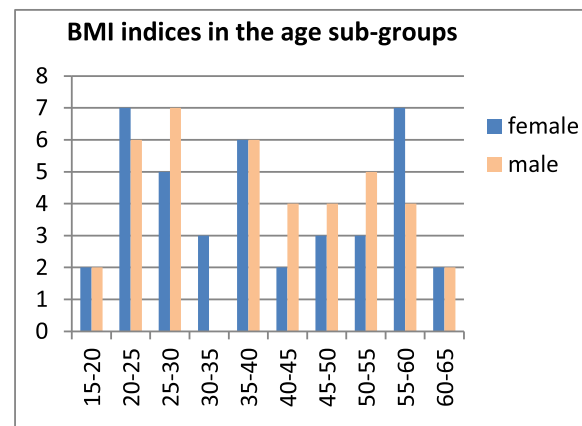

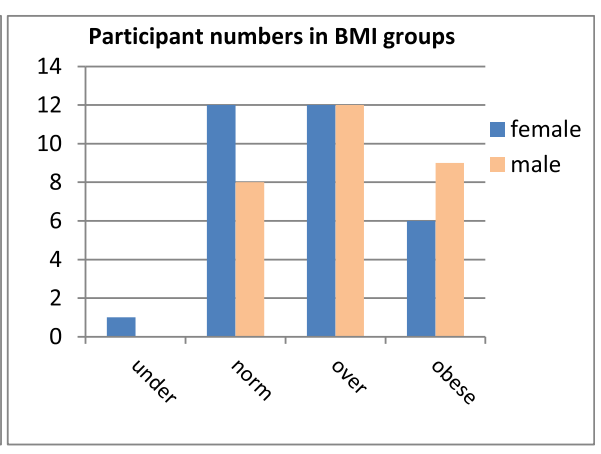

b

Fig. 1 Averaged BMI indices in the participant sub-groups according to the chronologic age (a), a number of the participants corresponding to BMI sub-groups, and average weight of the participants in BMI sub-groups (b). Coding: under, norm, over, obese = underweight, normal, overweight and obese correspondingly 
Table 1 Average weight of participants in chosen BMl sub-groups (underweight, normal, overweight, obese)

\begin{tabular}{|c|c|c|c|c|}
\hline & \multicolumn{2}{|l|}{ Male } & \multicolumn{2}{|l|}{ Female } \\
\hline & Average & St. deviation & Average & St. deviation \\
\hline Underweight (below 18.50) & - & - & 17.18 & - \\
\hline \multirow[t]{2}{*}{ Normal (18.50 to 24.99) } & 21.1 & 2.10 & 23.55 & 1.48 \\
\hline & & & 27.74 & \\
\hline Overweight (25.00 to 29.99) & 27.23 & 1.46 & 27.74 & 1.66 \\
\hline Obese (above 30) & 33.21 & 1.23 & 32.96 & 2.86 \\
\hline
\end{tabular}

There were no underweight male participants, and only one female

equal to $C A$ ) is about 50 years for male and 35 for female (Fig. 3). Interestingly, that corresponding "crossover points" that can be derived from the data by other studies are quite similar, even though the expressions for $B A$ calculations are different, and inclination of the linearized dependence of $B A$ from $C A$ is opposite. For example, crossover point $B A=C A$ for male is about 4550 years and for female about 35 years (Figs. 1 and 2, and Voitenko and Tokar 1983); crossover point $B A=$ $C A$ for male is about 50 years and for female-about 45 years (Fig. 1, and Kang et al. 2017).

In addition, the individual differences in the biologic age are generally increasing with the chronologic age, especially above 40 for female and above 50 for male participants. Individual differences are also significantly more pronounced for male participants (scatter for the $B A>C A$ condition is 42 to 62 years $C A$ for male and 20 to 38 years $C A$ for female). Also, it is useful to note, that individual scatter of the difference between the biologic and chronologic age is not very large in the interval 3040 years of age (near the crossover point $B A=C A$ ). Increasing individual scatter of the biologic age with the chronologic one could be explained by the growing impact of the external factors and accumulated health issues (at an early age, the main impact should belong to the genetic and other inherited factors).
Previously reported values for the perceived and biologic age were often carried out for both genders together (cumulative data) certain conclusions can be drawn. Cumulative perceived age calculated according to the approach developed in (Gunn et al. 2008; Coma et al. 2014) is almost coinciding with the biologic age for the male subjects (though in our estimations it is somewhat larger through almost the entire lifespan, Fig. 3). However, cumulative perceived age is larger than both chronologic and biologic age for the female subjects from a very early age and through almost entire lifespan (Fig. 3). So, with certain reservations, it may support the conclusion that males are looking closer to the "real age" $(B A)$ than females. Though existing data are not allowing making definite conclusions, one can speculate that as the social pressure towards "female beauty" is more pronounced, it should lead to the increased perceived age for the female.

Corresponding linear fit curves derived from our data are:

$$
\begin{gathered}
\text { For male : } \quad B A=0.508 C A+26.39, R^{2} \\
=0.397
\end{gathered}
$$

For female : $\quad B A=0.407 C A+20.92, R^{2}$ $=0.527$

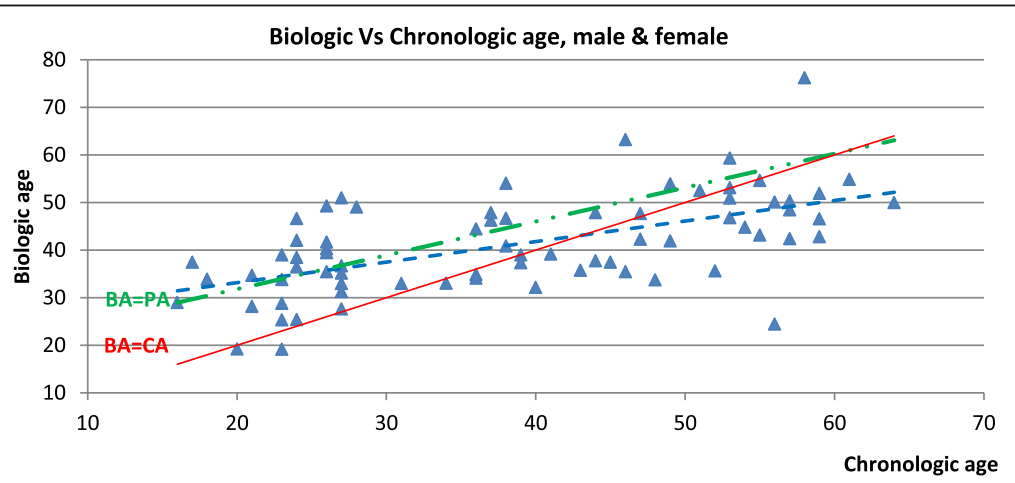

Fig. 2 Calculated biologic age (BA) dependence on the chronologic age (CA) for all participants. Solid line (red): biologic age is approximated by chronologic one; double dotted line (green): biologic age is approximated by chronologic one basing on the linear fit for the data from (Kaczmarek and Lasik 2006); dashed line: linear fit for experimental data (both male and female, $B A=0.431 C A+24.54, R^{2}=0.338$ ) 

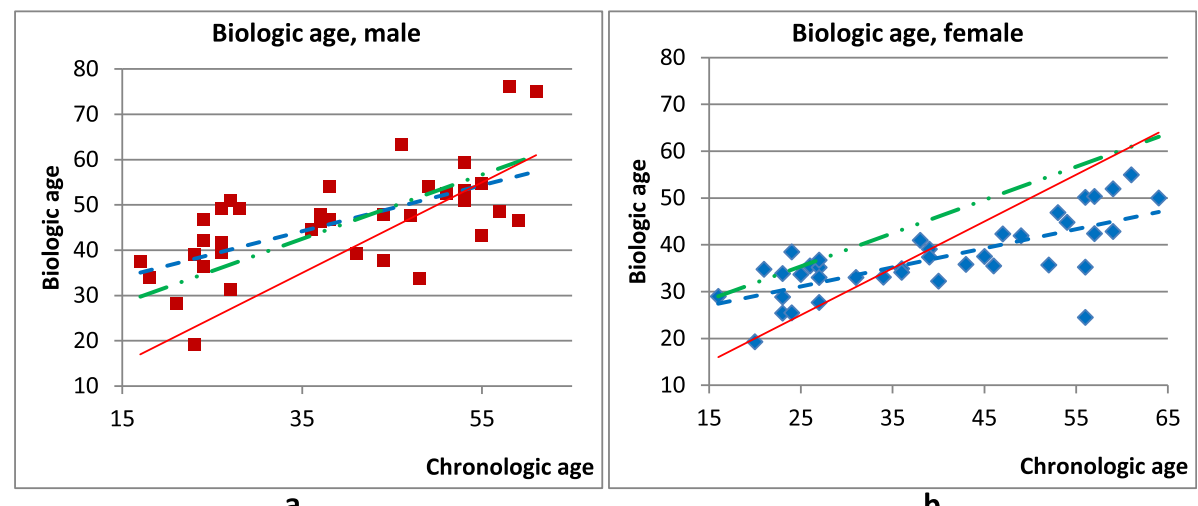

Fig. 3 Calculated biologic age $(B A)$ dependence on the chronologic age $(C A)$ for male (squares) and female (diamonds) participants. Solid line (red): biologic age is approximated by chronologic one; double dotted line (green): biologic age is approximated by chronologic age basing on the linear fit for the data from (Kaczmarek and Lasik 2006); dashed line: linear fit for experimental data $\left(B A=0.508 C A+26.39, R^{2}=0.397\right.$ for male, and $B A=0.407 C A+20.92, R^{2}=0.527$ for female)

$$
\begin{aligned}
& \text { Cumulative for all participants : } \\
& =0.431 C A+24.54, R^{2}=0.338
\end{aligned}
$$

Our studies were carried out in order to relate age parameters to the parameters of the skin. In attempt to identify the sub-groups that "do not need skin corrective intervention", and "may require intensive corrective intervention" three sub-groups were selected for each gender. During initial reasoning a group for "critical age" $(B A \sim C A)$ was defined as having this difference less than 5 years:

$$
|B A-C A|<5 \text { years }
$$

So the suggested choice for the three sub-groups was as follows: below and above the "critical" age ( $B A$ is clearly larger or clearly smaller than $C A$ ) and around the crossover age $(B A \sim C A)$. Individual scatter of the values in $B A$ vs $C A$ dependences is rather significant, so basing on all experimental data acquired we have adopted a simplified approach to the "critical age" sub-group selection linked to the biologic age but basing on the chronologic one. So finally, the sub-group selection criteria for the male subjects are below 40, between 40 and 50 , and above 50 years; for the female subjects are below 30, between 30 and 40 , and above 40 years (corresponds to the difference $\mid B A$ $C A \mid<2$ years). Therefore, the definition of the simplified criteria for the age sub-group selection is:

\section{Critical chronologic age group, male - between 40 and 50 years}

\section{Critical chronologic age group, female - between 30 and 40 years}

Further, we will refer to these groups as "early age", "critical age" and "late age" ones. Note, that though this choice is using the chronologic age, for the particular group of subjects it follows the criterion (8) on the biologic and chronologic age difference calculated using the approach defined above.

\section{Epidermal cell profile changes with the age difference BA-CA}

Skin cell and activity dependence on the age difference $(B A-C A)$ was studied using the cells extracted from the skin biopsy samples acquired from the gluteal region using punch skin biopsy. Figure 4 presents the dependence for relative numbers of epidermal fibroblasts (CD45-CD14-CD44+) and activated epidermal fibroblasts (CD45-CD14-CD44 + CD80+). Relative amount of fibroblasts and activated fibroblasts falls, and value scatter seems to be decreasing with the age for both male and female. In addition, the decrease rate of the activated fibroblasts numbers is faster for females, though their numbers are larger for female of young age $(\mathrm{BA}>\mathrm{CA})$.

Squares (linear fit: double-dotted line)-male participants; diamonds (linear fit: dashed line)-female participants. Note that a large positive difference $B A-C A$ corresponds to early age

Figure 5 presents the dependence for relative numbers of epidermal keratinocytes (CD49f + ) and activated keratinocytes (CD49f+HLA-DR+). Similar to the patterns described above for the epidermal fibroblasts, numbers of epidermal and activated epidermal keratinocytes decrease with the age, and there is a certain tendency for the scatter to decrease with age. Interestingly to note that though data scatter (individual differences for the same $B A-C A$ ) is rather large, trend lines for male and female tend to cross around $B A=C A$, though expressions for calculating biologic age $B A$ used in present research are different for male and female. 


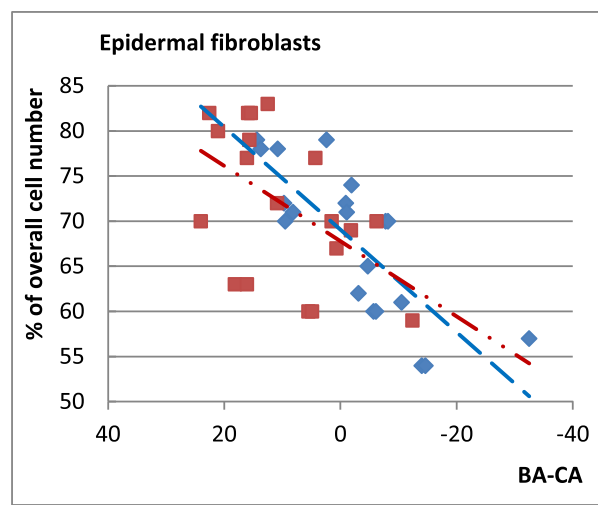

a

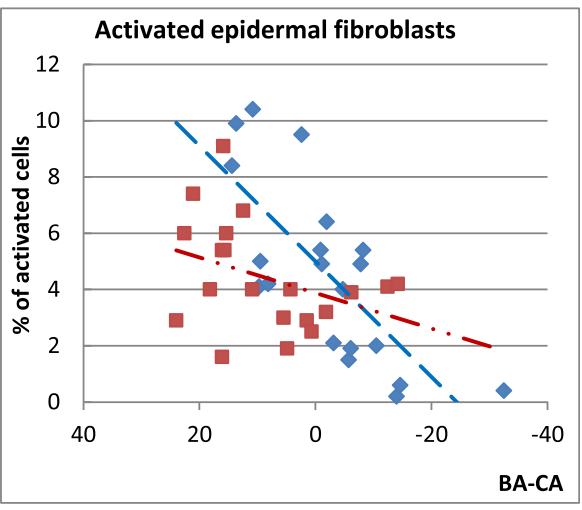

b

Fig. 4 Changes in the relative number of epidermal fibroblasts CD45-CD14-CD44+ (a) and activated epidermal fibroblasts CD45-CD14-CD44 + $\mathrm{CD} 80+(\mathbf{b})$ with the biologic and chronologic age difference BA-CA

Figure 6 presents the dependence for relative numbers of epidermal endotheliocytes CD146+ (a) and activated endotheliocytes of the type CD146+CD54-HLA-DR+ (b), of the type CD146+CD54+HLA-DR- (c), and of the type CD146+CD34+ (d). Corresponding fit line expressions are:

a. Male $y=-0.0009 x^{2}+0.0019 x+1.307, R^{2}=0.205$ female $y=0.0003 x^{2}+0.004 x+0.8886, R^{2}=0.0758$

b. Male $y=0.133 x+20.96, R^{2}=0.203$; female $y=$ $0.282 x+22.33, R^{2}=0.612$

c. Male $y=0.0002 x^{2}+0.0328 x+1.3056, R^{2}=0.0839$; female $y=-0.0014 x^{2}-0.0134 x+0.7905 ; R^{2}=$ 0.2081

d. $\quad$ Male $y=0.0010 x^{2}+0.1792 x+2.9962, R^{2}=0.2142$; female $y=0.0054 x^{2}+0.3225 x+4.4442 ; R^{2}=$ 0.5907

In all cases, cell number value is represented by a ratio of the specific cells to the overall cell count in standard flow cytometry tests.
During the analysis of measured parameter dependencies on the age difference $(B A-C A)$, we have tested if the normalization of the age difference would change the tendencies. It appears that plotting measured values against $B A-C A$ or normalized differences $(B A-C A) / B A$ or $(B A-C A) / C A$ does not change the trends, and in some cases, the trends can become clearer.

Figure 7 presents the trends in epidermal mastocyte (a) and activated epidermal mastocyte (b) number changes with normalized age difference $(B A-C A) / B A$. Corresponding fit line expressions are:

a. Male $y=0.144 x^{2}+0.991 x+4.005, R^{2}=0.039$; female: $y=4.990 x^{2}-1.255 \mathrm{x}+3.295, R^{2}=0.300$

b. Male $y=0.446 x^{2}+0.968 x+1.415, R^{2}=0.169$; female: $y=0.419 x^{2}-1.120 \mathrm{x}+1.217, R^{2}=0.142$

Figure 8 presents age difference dynamics of the numbers of epidermal monocytes/macrophages CD45 + CD14+ HLADR+ (a) and epidermal Ts lymphocytes

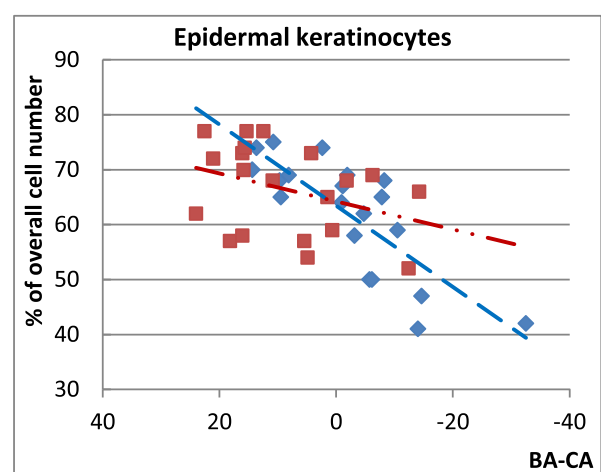

a

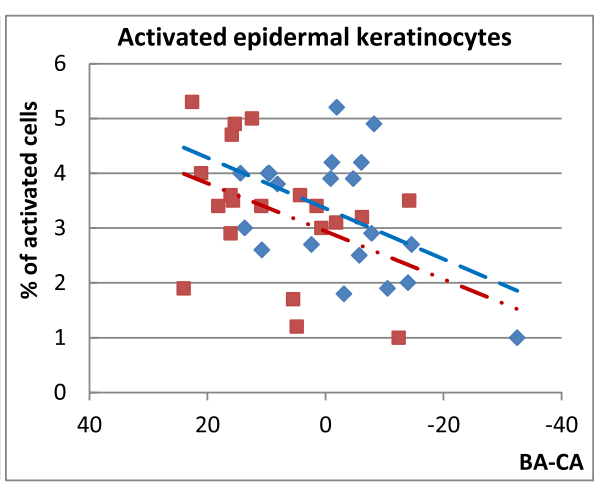

b

Fig. 5 Changes in the number of epidermal keratinocytes CD49f $+(\mathbf{a})$ and activated epidermal keratinocytes CD49+HLA-DR+ (b) with the biologic and chronologic age difference BA-CA. Squares (linear fit: double-dotted line) -male participants; diamonds (linear fit: dashed line) - female participants. Note that a large positive difference BA-CA corresponds to early age 

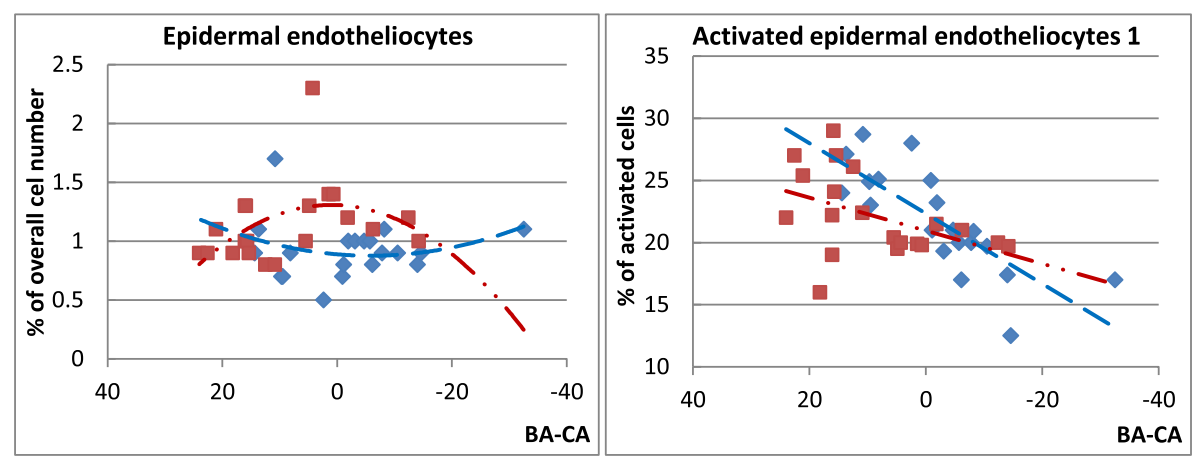

a

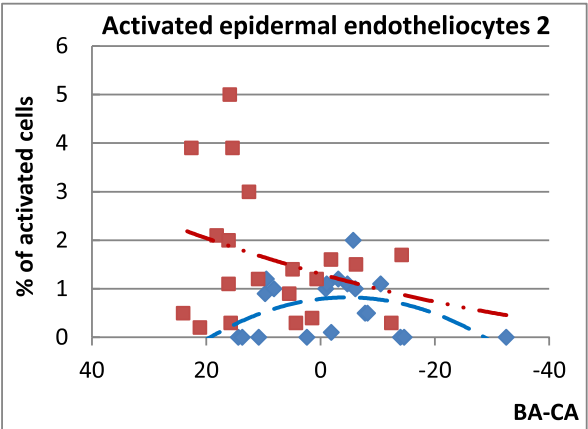

C

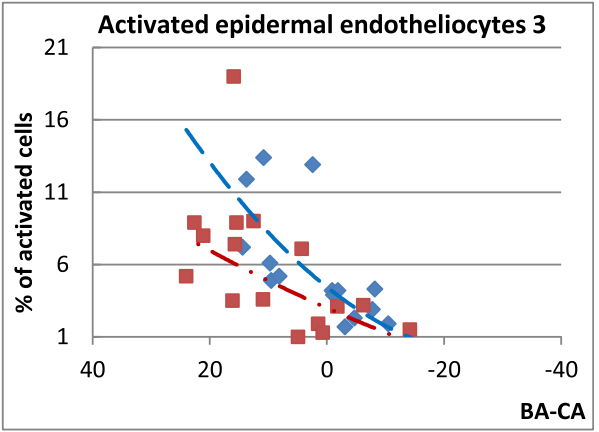

d

Fig. 6 Changes in the number of epidermal endotheliocytes CD146+ (a) and activated epidermal endotheliocytes CD146 + CD54-HLA-DR+ (b), CD146 + CD54 + HLA-DR- (c) and CD146 + CD34+ (d) with the biologic and chronologic age difference BA-CA (squares for male, double dotted fit lines; diamonds_-for female, dashed fit lines). Linear fit for activated endotheliocytes, and second-order polynomial fit lines—-the rest. Note that a large positive difference BA-CA corresponds to early age

CD45 + CD3 + CD4-CD8+ (b). Corresponding fit line expressions are:

a. Male $y=1.431 \mathrm{x}+5.921, R^{2}=0.162$; female: $y=$ $5.264 x+7.205, R^{2}=0.208$

b. Male $y=-4.480 x^{2}+3.179 x+3.317, R^{2}=$ 0.252; female: $y=0.682 x^{2}+0.234 x+3.874, R^{2}=$ 0.009
It was also worth checking, if the corresponding parameter values averaged for the subgroups according to the simplified "critical age" criterion basing on the chronologic age of the participants (see expressions 7-9 above) will show similar tendencies in the trends. Figures 9 and 10 present the numbers of epidermal keratinocytes, fibroblasts, endotheliocytes, and monocytes averaged for the sub-groups chosen according to $B A-C A$

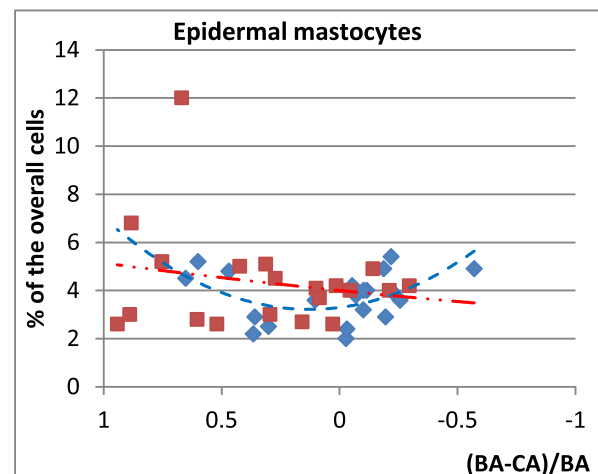

a

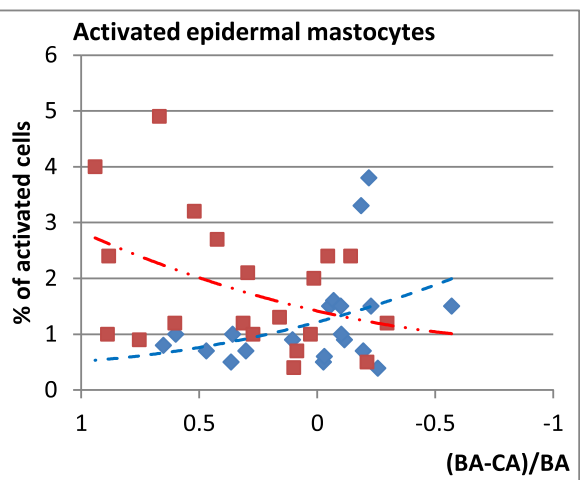

b

Fig. 7 Changes in the number of epidermal mastocytes CD249+ (a) and activated epidermal mastocytes CD249 + CD63+ (b) with the biologic and chronologic age difference BA-CA. Squares (second order polynomial fit: double-dotted line) —male participants; diamonds (second order polynomial fit: dashed line)_female participants. Note that a large positive difference BA-CA corresponds to early age 


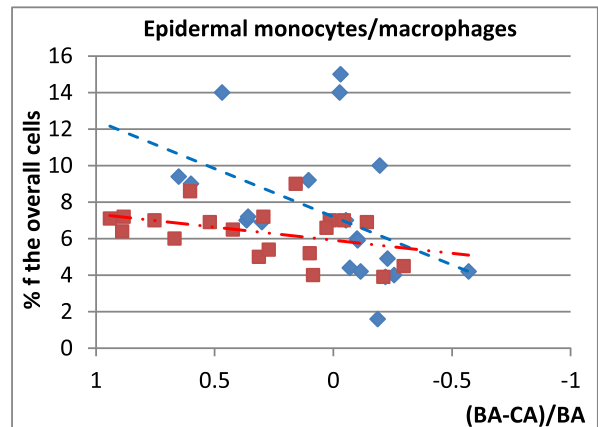

a

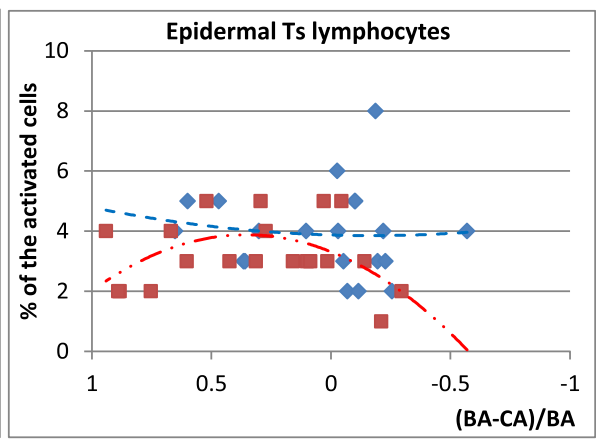

b

Fig. 8 Changes in the number of epidermal monocytes/macrophages CD45 + CD14 + HLADR+ (a) and epidermal Ts-lymphocytes (CD45 + CD3 + CD4-CD8+) (b) with the biologic and chronologic age difference BA-CA. Squares (double-dotted line) - male participants; diamonds (dashed line)_female participants. Note that a large positive difference $B A-C A$ corresponds to early age

criterion (age below, within and above "critical age interval").

Corresponding tendencies for the age sub-groups are also showing similar tendencies of decreasing numbers of epidermal fibroblasts, keratinocytes and epidermal endotheliocytes I and III.

Figure 11 illustrates the numbers of epidermal T-, Thand Ts-lymphocytes, B-lymphocytes, and NK-cells averaged for the sub-groups chosen according to $B A-C A$ criterion.

\section{Discussion}

Analysis of the data presented above shows that the overall number of the endotheliocytes seems relatively stable (though some smaller in male), but the number of activated endotheliocytes on average decreases with the age for both male and female (with the exception of the activated cells CD146 + CD54-HLA-DR+ showing opposite trends for male and female) (see Fig. 6). In addition, the dependences on the chronologic age for different types of activated endotheliocytes are quite different. The loss in active cells of the type CD146 + CD54 + HLA-DR- is quite significant, but the loss of active CD146 + CD34+ cells is more dramatic (close to the exponential dependence on chronologic age). Chronologic age dependence of the activated cells CD146 + CD54-HLA-DR+ numbers is very different for male and

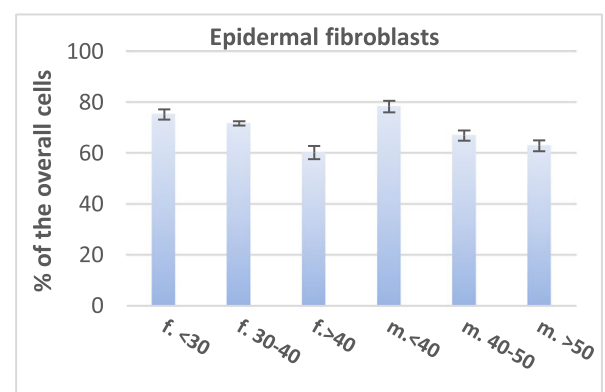

a

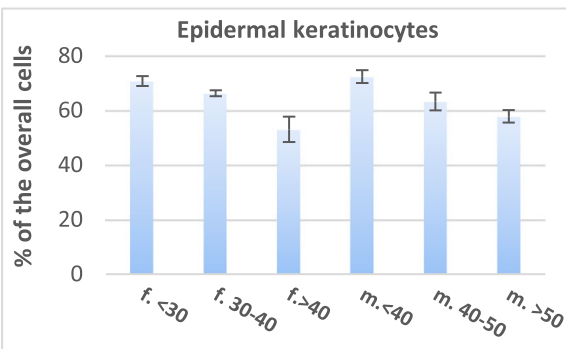

C

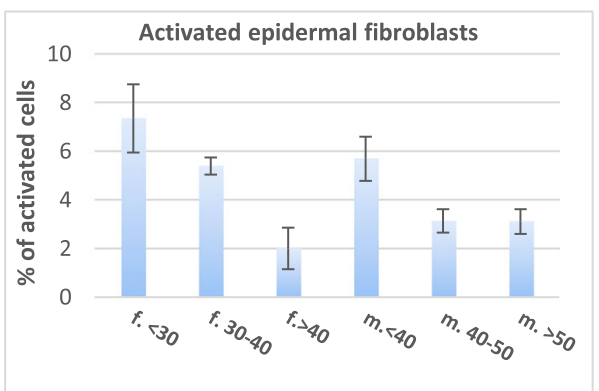

b

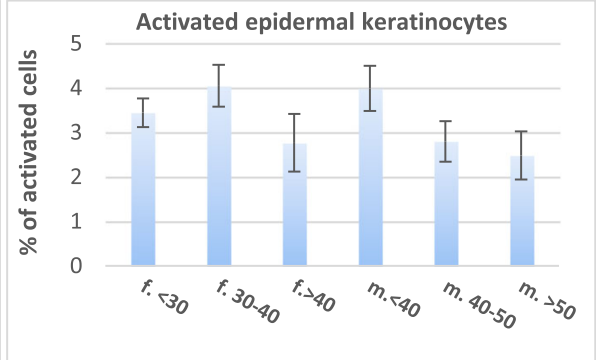

d

Fig. 9 Numbers of epidermal fibroblasts CD45-CD14-CD44+ (a), activated fibroblasts CD45-CD14-CD44 + CD80+ (b), epidermal keratinocytes CD48f (c) and activated epidermal keratinocytes CD49f + HLA-DR+ (d) averaged for the sub-population groups selected according to the "critical" chronologic age approach. 'm.' indicates male and 'f.' female participants 

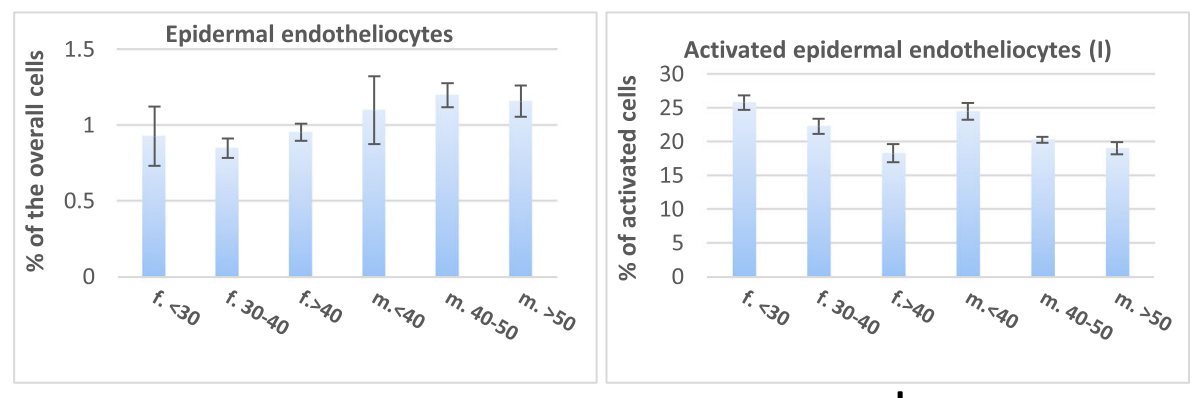

a

b
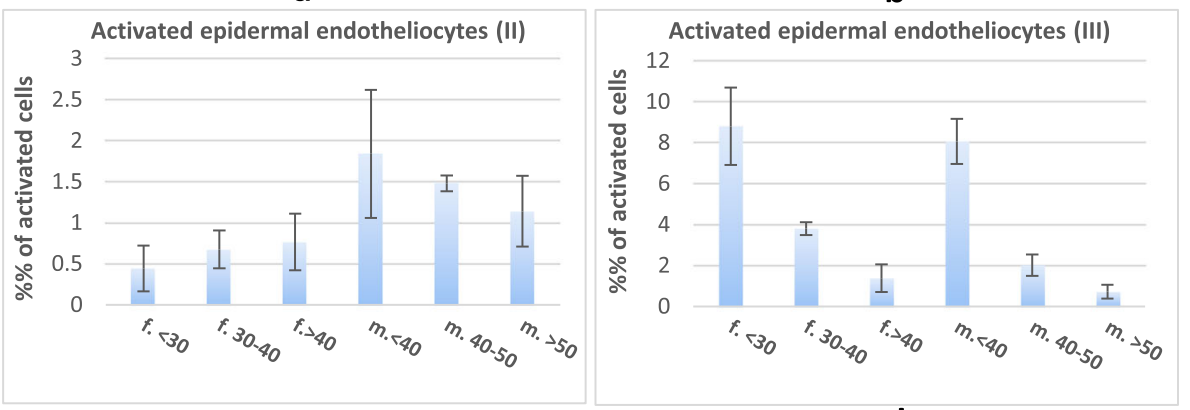

C
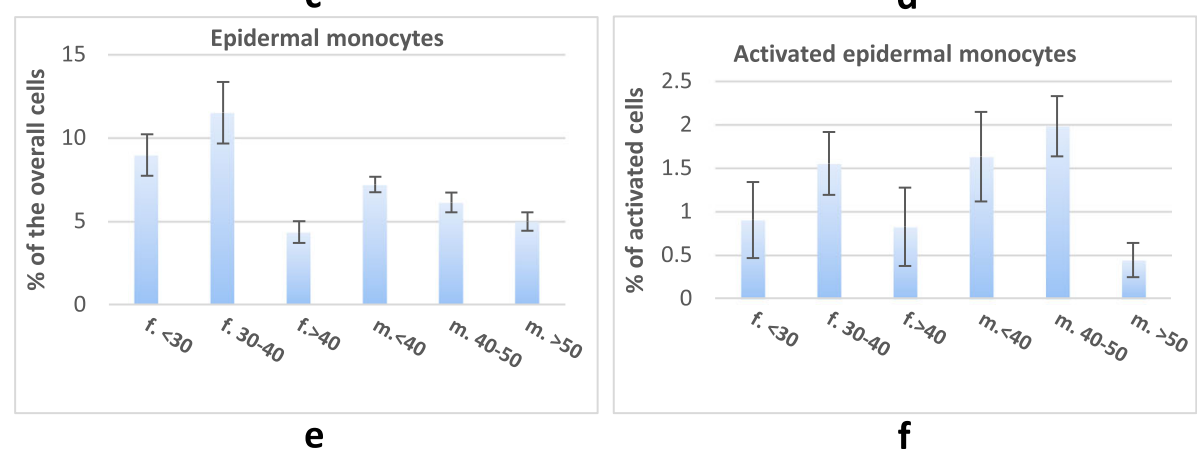

Fig. 10 Numbers of epidermal endotheliocytes CD146+ (a), activated endotheliocytes of the type CD146 + CD54 + HLA-DR- (b), CD146 + CD54 + HLA-DR+ (c), CD146 + CD34+ (d), and numbers of epidermal monocytes CD45 + CD14+ (e), and activated epidermal monocytes CD45 + CD14 + HLA-DR+ (f) averaged for the sub-population groups selected according to the "critical" chronologic age approach. 'm.' indicates male and 'f.' female participants

female. In the case of male, this number dramatically decreases until about 30 years of age and after seems to be rather stable but with increasing individual differences. In female, this number grows to about $40-50$ years of age and then seems tending to become stable, though individual differences are becoming quite significant not allowing getting any reasonable precision for the trend line computation. Also, note the difference in the trends: while the number and activity of the fibroblasts and keratinocytes (Figs. 4 and 5) are falling with the age difference $(B A-C A)$ almost linearly, the numbers of epidermal endotheliocytes and activated endotheliocytes show dynamics that are more complex. There is also a general falling trend of the discussed cell relative numbers with growing chronologic age above the threshold $B A=C A$. Also, in the majority of cases data scatter (individual differences for the same $B A-C A$ ) is rather large for younger age, trend lines for male and female tend to cross or have extremum close to $B A=C A$, though expressions for calculating biologic age $B A$ used in the present research are different for male and female participants.

Analysis of the data related to the epidermal mastocytes (Fig. 7) indicates that their overall number (CD249+) is rather stable through the entire life span for both male and female with some tendency to decrease in the middle age. The dynamics of activated mastocytes (CD249 + 63+) numbers is quite similar to the one of the activated endotheliocytes CD146 + CD54-HLA-DR+ (Fig. 6) and is quite different for male and female. In the case of male, this number significantly decreases until about 40 years of age and after seems to be rather stable, with the tendency to decrease further after about 50 years, but with increasing individual differences. In female, this number grows to about 30 years of age and then seems tending to stable 


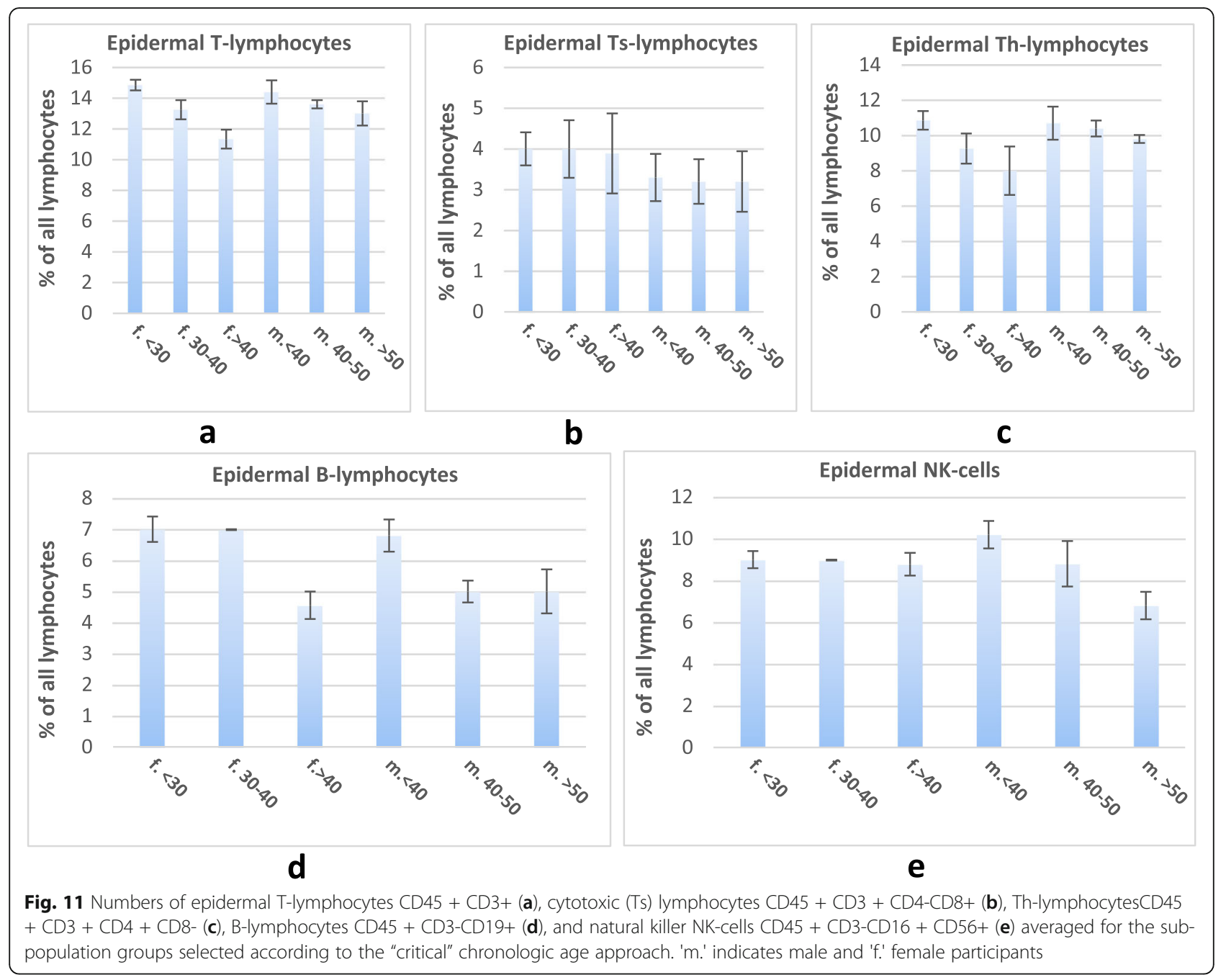

value, though individual differences are becoming quite significant to get any reasonable precision for the trend line. In addition, all trends in the parameter dependencies are becoming more clear if the parameters are plotted against "normalized age difference" $(B A-C A) / B A$, and less clear if plotted against $(B A-C A) / C A$. And while the individual difference between the epidermal mastocyte numbers for both male and female and activated mastocyte numbers for male decreases with the age (similar as for other measured parameters), scatter for activated mastocyte numbers for male is increasing.

Numbers of epidermal monocytes/macrophages (Fig. 8) are almost stable vs $B A-C A$, with the slight tendency for decreasing with the age, and their numbers are similar for male and female with the decline rate for female being slightly higher. Numbers of the activated epidermal monocytes/macrophages CD45 + CD14 + HLADR + are similar for male and female and show a strong tendency to decrease with the age (changing about twice for the age between 18 and 60). The general trend of the monocyte and macrophage numbers to decrease with the age is in line with the findings reported by other researchers reflecting the impact of the age on the innate immunity (Kupper and Fuhlbrigge 2004; Alonso-Fernández and de la Fuente 2011; Castelo-Branco and Soveral 2014; Martínez de Toda et al. 2016; Csaba 2019).

Analysis of the age difference dependence for the other measured factors shows the following trends. Numbers of the epidermal Th-lymphocytes CD4 + CD8- and epidermal T-lymphocytes CD45 + CD3+ are showing very similar dynamics. They are having similar numbers for male and female in the early life, and fall significantly with the age (close to linear trend vs $B A-C A$ ). However, in the case of female, the decrease rate is higher (about $20 \%$ decrease for male and about $40 \%$ for female for the age between 18 and 60). Numbers of the epidermal Ts cells CD45 + CD3 + CD4-CD8+ are very similar for male and female showing only a slight tendency to decrease with the age. Numbers of the epidermal B lymphocytes CD19+ show very similar trends for male and 
female with a significant decrease rate with the age (about twice for the age between 18 and 60). Numbers of the epidermal NK cells CD3-16 + 56+ have significantly different age dynamics for male and female, though in both cases declining with the age. The decline rate for male is also more pronounced than that for female (about $40 \%$ for male and about $10 \%$ for less for female for the age between 18 and 60). Overall results are similar to the findings by other researchers reporting declining humoral and cellular immunity functions with increasing age (and corresponding decrease in the numbers of B-lymphocytes and T-lymphocytes, (Kupper and Fuhlbrigge 2004; Alonso-Fernández and de la Fuente 2011; Castelo-Branco and Soveral 2014; Martínez de Toda et al. 2016; Csaba 2019). The same time we have not detected increasing with age numbers of NK cells as it is reported elsewhere for the blood test measurements (Martínez de Toda et al. 2016; Csaba 2019). Differences between the parameters measured for male and female are quite clear, which was also mentioned by other researchers. For example, it was claimed that overall numbers of $\mathrm{T}$ cells "are higher in females as a whole" (Csaba 2019). However, in our case, such a conclusion can only be related to the numbers of Ts-lymphocytes.

Though a scatter of the measured values is rather significant, it is already possible to conclude that significant changes in a number of parameters used to assess skin aging behave differently for the age groups selected according to the difference $B A-C A$ below and above zero. Trend lines for the majority of studied parameters for female and male participants are crossing or converging close to $B A=C A$. Majority of the parameters exhibit decreasing trends with growing age (falling difference $B A-C A$ ), but in few cases there are dependences with extremum values around $B A=C A$.

Corresponding parameter values averaged for the subgroups chosen according to the simplified "critical age" criterion basing on the chronologic age of the participants (see expressions 7-9 above) show similar tendencies in the trends. Measured dermal fibroblast and keratinocyte numbers (Fig. 9) are generally decreasing with the age, though dependence with maximum for the female group near the critical age is well pronounced. Measured overall amount of epidermal endotheliocytes is nearly stable with the age, but certain difference for male and female can be seen (Fig. 10a). But while counts of activated epidermal endotheliocytes of the types I and III falls with the age for both male and female (Fig. 10b, d), numbers of activated epidermal endotheliocytes for male are falling, and for female are growing with the age (Fig. 10c) also showing significant difference in the average values over the age groups. Epidermal monocyte and activated monocyte counts in female have a maximum around critical age and a similar trend is recorded for the activated monocytes in male, but overall monocyte counts for male are steadily falling with the age (Fig. 10e, f).

Interestingly, the tendencies for the age dependencies of the parameters averaged for the selected age subgroups in many cases still show the changes in the trends around "critical age" (clearly—Figs. 9d, 10a, e, f; to a certain extent-Figs. 9b, c, 10d). Again, in some cases, one can see the clear difference between the tendencies for the male and female participants (Fig. 9d; Fig. 10a, c, e; Fig. 11d, e). For example, numbers of epidermal $\mathrm{T}$, Th and Ts lymphocytes, B lymphocytes, and NK cells averaged for the age sub-groups (Fig. 11) are either rather stable or decreasing with the age, certain differences between male and female participants are present (Fig. 11d, e).

Interestingly, similar tendencies for the age difference $B A-C A$ having extremum were reported earlier. For example, Kang et al. have reported that the corrected $B A$ $C A$ difference for male subjects showed a tendency to have maximum for 40-60 years, and was clearly changing sign (negative-, positive-negative), and was increasingly positive for all age groups with females. Note that in this research, age sub-groups were selected in a different way: young -20 to 40 years, middle age -40 to 60 , old age $>60$.

\section{Conclusions}

Basing on the discussed experimental results one can conclude that dependencies of many critical parameters reflecting skin cellular profile on the difference of biologic age $B A$, calculated using chosen Eqs. (2) and (3), and the chronologic age $C A$ are changing trends in the vicinity of the point $B A=C A$. These studies already provide certain support for the validity of the suggested hypothesis that a difference between the chronologic and biologic age can be used as an indicator of skin aging.

Tendencies for the parameters reflecting skin cellular profile averaged for the selected age groups also show differences for male and female subjects. Trend changes for the "early age", "critical age" (biologic and chronologic age difference is less than 5 years) and "late age" groups are also detectable around "critical age". And though the chosen criterion for the "critical age" sub-group selection (5-year difference for $B A$ and $C A$ ) is rather arbitrary, it can be quite useful for practical applications.

With all reservations related to the relatively small number of subjects ( 40 male and 40 female), it still can be concluded that the difference of biologic and chronologic age can be used as an express indicator of skin aging. In addition, using different expressions for calculating male and female biologic age provides better grounds for using biologic and chronologic age difference as an indicator helping to formulate individualized approach to the skin treatment. The following paper will describe further 
research on the correlations between skin roughness, blood immune status, and calculated biologic age providing further support of the formulated hypothesis. Further research should be aimed at the improvements to the expressions used for biologic age calculations, keeping in mind the practicality of acquiring the needed parameters, and at improving the corresponding statistics widening the groups of study participants and monitoring longterm changes in the corresponding $B A$ values with aging of the same individuals.

\section{Abbreviations}

BA: Biologic age; BC: Blood cholesterol level; BMI: Body mass index; CA: Chronologic age; FVC: Forced vital lung capacity; PA: Perceived age; SBP: Systolic blood pressure; UC: Urea concentration in urine

\section{Acknowledgements}

Authors express their acknowledgements to Professor Vladimir Kozlov from the Institute of Clinical and Experimental Immunology for fruitful discussions.

\section{Authors' contributions}

The main idea of the research belongs to YS; YS and AK were the authors of the main hypothesis; designing, organizing and performing experiments were done by YS, EK, IU and DK; data analysis was done by AK. All authors read and approved the final manuscript.

\section{Funding}

Studies were carried out within the current research program of the Institute of Clinical Immunology and no external funding was received.

\section{Availability of data and materials}

The data supporting findings of this study are available from the Institute of Clinical and Experimental Immunology but restrictions apply to the availability of these data, which were used under license for current study, and so are not publically available. Data are however available from the authors upon request and with permission of the Institute of Clinical and Experimental Immunology.

\section{Ethics approval and consent to participate}

All participants were properly informed on the nature of studies and specific procedures and gave signed written consent to participate. The consent forms and the plans for the research were approved by the Ethics Commission of the Institute of Clinical Immunology according to the formal requirements issued by the State Department of Health of Russian Federation.

\section{Consent for publication}

All participants and authors gave their consent for the publication of the study results, and a formal consent for publication was granted by the Research Council of the Institute of Clinical and Experimental Immunology. It is also confirmed that the work conforms to the principles of the WHO Helsinki declaration.

\section{Competing interests}

The authors declare that they have no competing interests.

\section{Author details}

${ }^{1}$ Institute of Clinical Immunology, Tyumen branch, Kotovskogo str., 5, Tyumen, Russia. ${ }^{2}$ SportsTech Research Centre, Mid Sweden University, Akademigatan 1, Östersund, Sweden.

Received: 15 June 2019 Accepted: 14 November 2019

Published online: 20 December 2019

\section{References}

Alonso-Fernández $\mathrm{P}$, de la Fuente $\mathrm{M}$. Role of immune system in aging and longevity. Current Aging Science 2011;4:78-100. PMID: 21235494.
Anderson RR, Parrish JA. The optics of human skin. J Invest Dermatol. 1981; 77:13-9 https://doi.org/10.1111/1523-1747.ep12479191.

Anderson RR, Parrish JA. Optical Properties of Human Skin. In: Regan JD, Parrish JA, editors. The Science of Photomedicine. Boston, MA: Photobiology. Springer; 1982. https://doi.org/10.1007/978-1-4684-8312-3_6.

Beloserova LM. Algorythm for designing biologic age calculation expressions. Esthetic Medicine (Эстетическая Медицина, paper in Russian). 2006;5: 199-204.

Belsky DW, Caspi A, Houts R, Cohen HJ, Corcoran DL, Danese A, et al. Quantification of biological aging in young adults. Proc Natl Acad Sci U S A. 2015; https://doi.org/10.1073/pnas.1506264112.

Belsky DW, Huffman KM, Pieper CF, Shalev I, Kraus WE. Change in the Rate of Biological Aging in Response to Caloric Restriction: CALERIE Biobank Analysis. J Gerontol A Biol Sci Med Sci. 2017;73:4-10 https://doi.org/10. 1093/gerona/glx096.

Berry DS, McArthur LZ. Perceiving character in faces: The impact of age-related craniofacial changes on social perception. Psychol Bull 1986;100:3-18. PMID: 3526376.

Bhomick PC, Rao KS. Toxic Shades- Chemicals in Cosmetics that Matters. J Appl Chem 2014;3 (2):436-439. ISSN: 2278-1862.

Borkan GA, Norris AH. Assessment of Biological Age Using A Profile of Physical Parameters. J Gerontol. 1980;35:177-84 https://doi.org/10.1093/ geronj/35.2.177.

Brdar I, Tkalcic M, Bezinovic P. Women's cosmetics use and self-concept. Studia Psychologica (Bratislava) 1996;38:45-54. ISSN: 0039-3320.

Brown KS, Forbes WF. Concerning the estimation of biological age. Gerontology. 1976;22:428-37 https://doi.org/10.1159/000212155.

Bulpitt CJ, Shipley MJ, Broughton PM, Fletcher AE, Markowe HL, Marmot MG, et al. The assessment of biological age: A report from the Department of Environment Study. Aging Clin Exp Res 1994;6:181-191. PMID: 7993926.

Cash TF, Cash DW. Women's use of cosmetics: psychosocial correlates and consequences. Int J Cosmet Sci. 1982;4:1-14 https://doi.org/10.1111/j.14672494.1982.tb00295.x.

Castelo-Branco C, Soveral I. The immune system and aging: a review. Gynecol Endocrinol. 2014;30:16-22 https://doi.org/10.3109/09513590.2013.852531.

Chalyk NE, Bandaletova TY, Kyle NH, Petyaev IM. Morphological Characteristics of Residual Skin Surface Components Collected from the Surface of Facial Skin in Women of Different Age. Ann Dermatol 2017;29:454-461. https://doi.org/ 10.5021/ad.2017.29.4.454

Cheng FS, Ooi CS, Ting DH. Factors affecting consumption behavior of metrosexual toward male grooming products. International Review of Business Research Papers. 2010;6:574-90.

Cho IH, Park KS, Lim CJ. An empirical comparative study on biological age estimation algorithms with an application of Work Ability Index (WAI). Mech Ageing. 2010;131:69-78 https://doi.org/10.1016/j.mad.2009.12.001.

Christensen K, lachina M, Rexbye H, Tomassini C, Frederiksen H, McGue M et al. "Looking Old for Your Age": Genetics and Mortality. Epidemiology. 2004;15: 251-252. PMID: 15127920.

Cohen AA, Milot E, Li Q, Bergeron P, Poirier R, Dusseault-Bélanger F, et al. Detection of a novel, integrative aging process suggests complex physiological integration. PLoS One. 2015; https://doi.org/10.1371/journal. pone.0116489.

Coltman CE, Steele JR, McGhee DE. Effect of aging on breast skin thickness and elasticity: implications for breast support. Skin Res Technol. 2017;23:303-11 https://doi.org/10.1111/srt.12335.

Coma M, Valls R, Mas JM, Pujol A, Herranz MA, Alonso V, Naval J. Methods for diagnosing perceived age on the basis of an ensemble of phenotypic features. Clin Cosmet Investig Dermatol. 2014;7:133-137. https://doi.org/10. 2147/CCID.S52257

Cossio-Bolaños M, Gómez Campos R, Andruske CL, Viveros Flores A, LuarteRocha C, Olivares PR, et al. Physical Growth, Biological Age, and Nutritional Transitions of Adolescents Living at Moderate Altitudes in Peru. Int J Environ Res Public Health. 2015;12:12082-94 https://doi.org/10 3390/ijerph121012082.

Csaba G. Immunity and longevity. Acta Microbiol Immunol Hung. 2019;66:1-17 https://doi.org/10.1556/030.65.2018.029.

de Groot AC. Dermatological Problems Linked to Perfumes. In: Handbook of Cosmetic Science and Technology. Eds. Barel AO, Maibach HI. CRC Press, 2001: 89-94. ISBN: 9781842145647.

Dean W. Biological aging measurement - clinical applications. Center for Bio Gerontology, Los Angeles, 1986. ISBN-13: 978-0937777008. 
Dean W. Biological aging measurement. Arch Gerontol Geriatr 1998;1:64-85. PMID: 3052338

Dykiert D, Bates TC, Gow AJ, Penke L, Starr JM, Deary IJ. Predicting mortality from human faces. Psychosom Med. 2012;74:560-6 https://doi.org/10.1097/PSY 0b013e318259c33f

Edwards C, Heggie R, Marks R. A study of differences in surface roughness between sun-exposed and unexposed skin with age. Photodermatol Photoimmunol Photomed 2003;19:169-174. PMID: 12925187.

Farage MA, Miller KW, Elsner P, Maibach HI. Characteristics of the aging skin. Adv Wound Care (New Rochelle). 2013;2:5-10. https://doi.org/10.1089/wound.2011.0356

Farkas JP, Pessa JE, Hubbard B, Rohrich RJ. The Science and Theory behind Facial Aging. Plast Reconstr Surg Glob Open. 2013; https://doi.org/10.1097/GOX. ob013e31828ed1da.

Freis O, Perie G, Rathjens A. Correlating aging with skin's mechanical and optical properties. Cosmetics \& Toiletries. 2014;129:66-75.

Furukawa T, Inoue M, Kajiya F, Inada H, Takasugi S. Assessment of biological age by multiple regression analysis. J Gerontol. 1975;30:422-34 https://doi.org/10. 1093/geronj/30.4.422.

Gilchrest BA. Skin aging 2003: recent advances and current concepts. Cutis. 2003; 72:5-10; discussion 10. PMID: 14533824.

Gilchrest BA, Krutmann J. Skin Aging. Springer, Berlin, Germany, 2006. ISBN 978-3540-32953-4

Girdwichai N, Chanprapaph K, Vachiramon V. Behaviors and Attitudes Toward Cosmetic Treatments Among Men. J Clin Aesthet Dermatol 2018; 11: 42-48. PMID: 29607001.

Graham JA, Kligman AM. Physical attractiveness, cosmetic use and self-perception in the elderly. Int J Cosmet Sci. 1985;7:85-97 https://doi.org/10.1111/j.14672494.1985.tb00399.x.

Gruenewald TL, Seeman TE, Ryff CD, Karlamangla AS, Singer BH. Combinations of biomarkers predictive of later life mortality. Proc Natl Acad Sci U S A. 2006; 103:14158-63 https://doi.org/10.1073/pnas.0606215103.

Guinot C, Malvy DJ, Ambroisine L, Latreille J, Mauger E, Tenenhaus M, et al. Relative contribution of intrinsic vs extrinsic factors to skin aging as determined by a validated skin age score. Arch Dermatol. 2002;138:1454-60 https://doi.org/10.1001/archderm.138.11.1454

Gunn DA, Murray PG, Tomlin CC, Rexbye H, Christensen K, Mayes AE. Perceived age as a biomarker of ageing: a clinical methodology. Biogerontology. 2008; 9:357-64 https://doi.org/10.1007/s10522-008-9141-y.

Gunn DA, Rexbye H, Griffiths CE, Murray PG, Fereday A, Catt SD, et al. Why Some Women Look Young for Their Age. PLoS One. 2009;4:e8021 https://doi.org/ 10.1371/journal.pone.0008021.

Gupta MA. Aging skin and quality of life. In: R. Rajgopalan, E.F. Sheretz, R.T. Anderson, editors. Care management of skin diseases: life quality and economic impact. Marcel Dekker, New York; 1998:245-51. ISBN-13: 978-0262140768.

Gupta MA, Gilchrest BA. Psychosocial aspects of aging skin. Dermatol Clin. 2005; 23:643-8 https://doi.org/10.1016/.j.det.2005.05.012.

Gupta MA., Gupta AK. Psychological impact of aging and the skin. Chapter 24. In: Koo JYM, Lee CS, Editors. Psychocutaneous medicine. Marcel Dekker, New York; 2003:365-73. https://doi.org/10.1201/9780203911877

Gupta S, Arora S. Factors influencing the Consumption Pattern of Male Cosmetics in Delhi by an Urban Male. IOSR J Bus Manag. 2013;15:29-36 https://doi.org/ 10.9790/487X-1522936.

Hall DA. Biology of aging-structural and metabolic aspects. In: Brocklehurst JC, editor. Textbook of Geriatric Medicine and Gerontology. Edinburgh: Churchill Livingstone; 1985. p. 46-61.

Holly AC, Melzer D, Pilling LC, Henley W, Hernandez DG, Singleton AB, et al. Towards a gene expression biomarker set for human biological age. Aging Cell. 2013;12:324-6 https://doi.org/10.1111/acel.12044.

Introna F, Campobasso CP. Biological Vs Legal Age of Living Individuals. In: Forensic Anthropology and Medicine: Complementary Sciences from Recovery to Cause of Death. Schmitt A, Cunha E, Pinheiron J, Editors. Humana Press, NJ, 2006, p. 57-82. https://doi.org/10.1002/oa.920

Jackson SHD, Weale MR, Weale RA. Biological age - What is it and can it be measured? Arch Gerontol Geriatr. 2003;36:103-15 https://doi.org/10.1016/ S0167-4943(02)00060-2

Jacobi U, Chen M, Frankowski G, Sinkgraven R, Hund M, Rzany B, et al. In vivo determination of skin surface topography using an optical 3D device. Skin Res Technol. 2004;10:207-14 https://doi.org/10.1111/j.1600-0846.2004.00075.x.

Jee H. Development of Biological Age Prediction Model Based on the Osseous Parameters and the Effects of Endurance Exercise Duration and Falling on Aging. Exerc Sci. 2016;25:60-7 https://doi.org/10.15857/ksep.2016.25.1.60.
Jia L, Zhang W, Chen X. Common methods of biological age estimation. Clin Interv Aging. 2017;12:759-72 https://doi.org/10.2147/CIA.S134921.

Jia L, Zhang W, Jia R, Zhang H, Chen X. Construction Formula of Biological Age Using the Principal Component Analysis. BioMed Research International. 2016, Article ID 4697017. https://doi.org/10.1155/2016/4697017

Johnson TE. Recent results: Biomarkers of aging. Exp Gerontol. 2006;41:1243-6 https://doi.org/10.1016/j.exger.2006.09.006.

Kaczmarek M, Lasik E. Correlations of biological age in postmenopausal life. Przegląd Antropologiczny - Anthropological Review. 2006;69:15-26.

Kang YG, Suh E, Chun H, Kim SH, Kim DK, Bae CY. Models for estimating the metabolic syndrome biological age as the new index for evaluation and management of metabolic syndrome. Clin Interv Aging. 2017;12:253-61 https://doi.org/10.2147/CIA.S123316.

Khan AF, Khan MF. A Study on the Awareness of Product Ingredients among Women Skincare Users in State Of Madhya Pradesh. IOSR Journal of Business and Management (IOSR-JBM). 2013;14:65-72.

Kim S, Jazwinski SM. Quantitative measures of healthy aging and biological age. Healthy Aging Res. 2015;4. pii: 26. https://doi.org/10.12715/har.2015.4.26

Klemera P, Doubal S. A new approach to the concept and computation of biological age. Mech Agng Dev. 2006;127:240-8 https://doi.org/10.1016/j. mad.2005.10.004

Kligman AM, Graham JA. The psychology of appearance in the elderly. Dermatol Clin 1986:4:501-507. PMID: 3521995.

Koblenzer CS. Psychologic aspects of aging and the skin. Clin Dermatol 1996;14: 171-177. PMID: 9117984.

Koblenzer CS. Psychosocial aspects of beauty: how and why to look good. Clin Dermatol. 2003:21:473-5 https://doi.org/10.1016/..clindermatol.2003.11.010.

Kokoi I. Female Buying Behaviour Related to Facial Skin Care Products. A Comparison Between Young and Middle-aged Women. LAP Lambert Academic Publishing. 2011:ISBN-13:978-3845443249.

Konduracka E, Krzemieniecki K, Gajos G. Relationship between everyday use cosmetics and female breast cancer. Pol Arch Med Wewn. 2014;124:264-9. 24694726.

Krištić J, Vučković F, Menni C, Klarić L, Keser T, Beceheli I, et al. Glycans are a novel biomarker of chronological and biological ages. J Gerontol A Biol Sci Med Sci. 2014;69:779-89 https://doi.org/10.1093/gerona/glt190.

Krueger N, Luebberding S, Oltmer M, Streker M, Kerscher M. Age-related changes in skin mechanical properties: a quantitative evaluation of 120 female subjects. Skin Res Technol. 2011;17:141-8 https://doi.org/10.1111/j.1365-2133. 1990.tb16127.x

Kupper TS, Fuhlbrigge RC. Immune surveillance in the skin: mechanisms and clinical consequences. Nat Rev Immunol. 2004;4:211-22 https://doi.org/10. 1038/nri1310.

Kwon YH, da Vitoria Lobo N. Age classification from facial images. Comput Vis Image Underst. 1999;74:1-21 https://doi.org/10.1006/cviu.1997.0549.

Lai M, Oruc I, Barton JJ. The role of skin texture and facial shape in representations of age and identity. Cortex. 2011;49:252-65 https://doi.org/ 10.1016/..cortex.2011.09.010.

Little T, Lewis T, Lundquist P. Beneath the skin. Hidden Liabilities, Market Risk and Drivers of Change in the Cosmetics and Personal Care Products Industry. Rose Foundation Report. Arlington, Virginia, 2007.

Ludwig FC, Smoke ME. The measurement of biological age. Exp Aging Res. 1980; 6:497-522 https://doi.org/10.1080/03610738008258384.

Luebberding S, Krueger N, Kerscher M. Mechanical properties of human skin in vivo: a comparative evaluation in 300 men and women. Skin Res Technol. 2014:20:127-35 https://doi.org/10.1111/stt.12094.

Maggio M, Guralnik JM, Longo DL, Ferrucci L. Interleukin-6 in aging and chronic disease: a magnificent pathway. J Gerontol A Biol Sci Med Sci. 2006;61:57584 https://doi.org/10.1093/gerona/61.6.575

Mann ER, Smith KM, Bernardo D, Al-Hassi HO, Knight SC, Hart AL. Review: Skin and the Immune System. J Clin Exp Dermatol. 2012;52:003 https://doi.org/10. 4172/2155-9554.S2-003.

Martínez de Toda I, Maté I, Vida C, Cruces J, De la Fuente M. Immune function parameters as markers of biological age and predictors of longevity. Aging. 2016:8:3110-9 https://doi.org/10.18632/aging.101116.

Masuda Y, Oguri M, Morinaga T, Hirao T. Three-dimensional morphological characterization of the skin surface micro-topography using a skin replica and changes with age. Skin Res Technol. 2014;20:299-306 https://doi.org/10. 1111/srt.12119.

Mather KA, Jorm AF, Parslow RA, Christensen $\mathrm{H}$. Is telomere length a biomarker of aging? A review. J Gerontol A Biol Sci Med Sci. 2011;66:202-13 https://doi. org/10.1093/gerona/glq180. 
Matts PJ. New Insights into Skin Appearance and Measurement. J Investig Dermatol Symp Proc. 2008;13:6-9 https://doi.org/10.1038/jidsymp.2008.6.

Misra A, Dhurandhar NV. Current formula for calculating body mass index is applicable to Asian populations. Nutr Diabetes. 2019;9:3 https://doi.org/10. 1038/s41387-018-0070-9.

Mitnitski A, Rockwood K. Biological age revisited. J Gerontol A Biol Sci Med Sci. 2014;69:295-6 https://doi.org/10.1093/gerona/glt137.

Montagna W, Carlisle K. Structural changes in aging skin. Br J Dermatol. 1990;122: 61-70 https://doi.org/10.1111/j.1365-2133.1990.tb16127.x.

Nakamura E, Miyao K, Ozeki T. Assessment of biological age by principal component analysis. Mech Agng Dev. 1988;46:1-18 https://doi.org/10.1016/ 0047-6374(88)90109-1.

Naylor EC, Watson RE, Sherratt MJ. Molecular aspects of skin ageing. Maturitas. 2011;69(3):249-56 https://doi.org/10.1016/j.maturitas.2011.04.011.

Nedelec B, Forget NJ, Hurtubise T, Cimino S, de Muszka F, Legault A, et al. Skin characteristics: normative data for elasticity, erythema, melanin, and thickness at 16 different anatomical locations. Skin Res Technol. 2016;22:263-75 https://doi.org/10.1111/srt.12256.

Nielsen KP, Zhao L, Stamnes JJ, Stamnes K, Moan JM. The optics of human skin: Aspects important for human health. In: Solar Radiation and Human Health. Espen Bjertness, Editor. Oslo: The Norwegian Academy of Science and Letters, 2008:35-45. ISBN: 9788270994854.

Nuttall FQ. Body Mass Index: Obesity, BMI, and Health A Critical Review. Nutr Today. 2015;50:117-28 https://doi.org/10.1097/NT.0000000000000092.

Passarino G, De Rango F, Montesanto A. Human longevity: Genetics or Lifestyle? It takes two to tango. Immun Ageing. 2016. https://doi.org/10.1186/s12979016-0066-z.

Porcheron A, Mauger E, Russell R. Aspects of facial contrast decrease with age and are cues for age perception. PLoS One. 2013;8:e57985. https://doi.org/10 1371/journal.pone.0057985.

Rawal R, Anshu. A Study on Impact of Agng on Self Esteem. Int.J.Curr.Microbiol. App.Sci. 2019;8:1747-51 https://doi.org/10.20546/ijcmas.2019.802.206.

Rodrigues L. EEMCO. EEMCO guidance to the in vivo assessment of tensile functional properties of the skin. Part 2: instrumentation and test modes. Skin Pharmacol Appl Ski Physiol. 2001;14:52-67 https://doi.org/10.1159/ 000056334

Safe Cosmetics for Young Children. A Guide for Manufacturers and Safety Assessors. European Directorate for the Quality of Medicines \& HealthCare (EDQM), 2012. ISBN-13: 9789287173379.

Sanders JL, Newman AB. Telomere Length in Epidemiology: A Biomarker of Aging, Age-Related Disease, Both, or Neither? Epidemiol Rev. 2013;35:112-31 https://doi.org/10.1093/epirev/mxs008

Shetage SS, Traynor MJ, Brown MB, Raji M, Graham-Kalio D, Chilcott RP. Effect of ethnicity, gender and age on the amount and composition of residual skin surface components derived from sebum, sweat and epidermal lipids. Skin Res Technol. 2014;20:97-107 https://doi.org/10.1111/srt.12091.

Simm A, Nass N, Bartling B, Hofmann B, Silber RE, Navarrete SA. Potential biomarkers of ageing. Biol Chem. 2008;389:257-65 https://doi.org/10.1515/BC.2008.034.

Smith T, Brownless L. Age assessment practices: a literature review \& annotated bibliography. Unicef, NY, 2011.

Sochung C. Body mass index and body composition scaling to height in children and adolescent. Ann Pediatr Endocrinol Metab. 2015;20:125-9 https://doi. org/10.6065/apem.2015.20.3.125

Sprott RL. Biomarkers of aging and disease: Introduction and definitions. Exp Gerontol. 2010:45:2-4 https://doi.org/10.1016/j.exger.2009.07.008.

Steele CM, Spencer SJ, Lynch M. Self-image resilience and dissonance: the role of affirmational resources. J Pers Soc Psychol. 1993;64:885-96 https://doi.org/10. 1037//0022-3514.64.6.885.

Stowe RP, Peek MK, Cutchin MP, Goodwin JS. Plasma cytokine levels in a population-based study: relation to age and ethnicity. J Gerontol A Biol Sci Med Sci. 2010;65:429-33 https://doi.org/10.1093/gerona/glp198.

Sturrock F, Pioch E. Making himself attractive: The growing consumption of grooming products. Mark Intell Plan. 1998;16:337-43 https://doi.org/10.1108/ 02634509810229955.

Teen Survival Guide: Health Tips for On-the-go Girls. Human Services, U.S. Department of Health, 2013. ISBN-13: 978-1492780847.

Trojahn C, Dobos G, Lichterfeld A, Blume-Peytavi U, Kottner J. Characterizing Facial Skin Agng in Humans: Disentangling Extrinsic from Intrinsic Biological Phenomena. Biomed Res Int, ID. 2015a:318586 https://doi.org/10.1155/2015/ 318586.
Trojahn C, Dobos G, Schario M, Ludriksone L, Blume-Peytavi U, Kottner J. Relation between skin micro-topography, roughness, and skin age. Skin Res Technol. 2015c;21:69-75 https://doi.org/10.1111/srt.12158.

Trojahn C, Schario M, Dobos G, Blume-Peytavi U, Kottner J. Reliability and validity of two in vivo measurements for skin surface topography in aged adults. Skin Res Technol. 2015b;21:54-60 https://doi.org/10.1111/srt.12156.

Uttley M, Crawford MH. Efficacy of a Composite Biological Age Score to Predict Ten-Year Survival Among Kansas and Nebraska Mennonites. Hum Biol. 1994; 66:121-44.8157261.

Voitenko VP, Tokar AV. The assessment of biological age and sex differences of human aging. Exp Aging Res. 1983;9:239-44 https://doi.org/10.1080/ 03610738308258458 .

Wang AS, Dreesen O. Biomarkers of Cellular Senescence and Skin Aging. Front Genet. 2018;9:247 https://doi.org/10.3389/fgene.2018.00247.

Watanabe M, Buch K, Fujita A, Christiansen CL, Jara H, Sakai O. MR relaxometry for the facial aging assessment: the preliminary study of the age dependency in the MR relaxometry parameters within the facial soft tissue. Dentomaxillofac Radiol. 2015;44:20150047 https://doi.org/10.1259/dmfr. 20150047.

Waters J. Cosmetics and the job market. In: Graham JA, Kligman AM, Editors. The psychology of cosmetic treatments. Praeger, New York; 1986:113-124. ISBN13: 978-0317046519.

Webster IW, Logie AR. A relationship between functional age and health status in female subjects. J Gerontol. 1976;31:546-50 https://doi.org/10.1093/geronj/ 31.5.546

Wiweko B, Prawesti DM, Hestiantoro A, Sumapraja K, Natadisastra M, Baziad A Chronological age vs biological age: an age-related normogram for antral follicle count, FSH and anti-Mullerian hormone. J Assist Reprod Genet. 2013; 30:1563-7 https://doi.org/10.1007/s10815-013-0083-1.

Woo MS, Moon KJ, Jung HY, Park SR, Moon TK, Kim NS, et al. Comparison of skin elasticity test results from the Ballistometer $\left({ }^{\oplus}\right)$ and Cutometer $\left({ }^{\oplus}\right)$. Skin Res Technol. 2014;20:422-8 https://doi.org/10.1111/srt.12134.

World Medical Association. World Medical Association Declaration of Helsinki. Ethical Principles for Medical Research Involving Human Subjects. JAMA. 2013:310:2191-4 https://doi.org/10.1001/jama.2013.281053.

York-Goldman D, Goldman PM. Beauty Basics for Teens: The Complete Skin-care, Hair-care, and Nail-care Guide for Young Women. York- Goldman Enterprises, Inc., 2001. ISBN: 0-609-80753-6.

Zhang S, Duan E. Fighting against Skin Aging: The Way from Bench to Bedside. Cell Transplant. 2018;27:729-38 https://doi.org/10.1177/0963689717725755.

\section{Publisher's Note}

Springer Nature remains neutral with regard to jurisdictional claims in published maps and institutional affiliations.

Ready to submit your research? Choose BMC and benefit from:

- fast, convenient online submission

- thorough peer review by experienced researchers in your field

- rapid publication on acceptance

- support for research data, including large and complex data types

- gold Open Access which fosters wider collaboration and increased citations

- maximum visibility for your research: over $100 \mathrm{M}$ website views per year

At $\mathrm{BMC}$, research is always in progress.

Learn more biomedcentral.com/submissions 